\title{
Ranitidine Loaded Biopolymer Floats: Designing, Characterization, and Evaluation
}

\author{
Abdul Karim, Muhammad Ashraf Shaheen, Tahir Mehmood, Abdul Rauf Raza, \\ Musadiq Aziz, and Badar Din
}

Department of Chemistry, University of Sargodha, Sargodha 40100, Pakistan

Correspondence should be addressed to Muhammad Ashraf Shaheen; mashaheen@uos.edu.pk

Received 17 June 2017; Revised 28 September 2017; Accepted 11 October 2017; Published 14 December 2017

Academic Editor: Somdet Srichairatanakool

Copyright (C) 2017 Abdul Karim et al. This is an open access article distributed under the Creative Commons Attribution License, which permits unrestricted use, distribution, and reproduction in any medium, provided the original work is properly cited.

\begin{abstract}
The float formulation is a strategy to improve the bioavailability of drugs by gastroretentive drug delivery system (GRDDS). A drug delivery model based on swellable and reswellable low density biopolymers has been designed to evaluate its drug release profile using ranitidine (RNT) as a model drug and formulations have been prepared utilizing $3^{2}$ factorial designs. The drug release (DR) data has been subjected to various kinetic models to investigate the DR mechanism. A reduction in rate has been observed by expanding the amounts of PSG and LSG parts, while an expansion has been noted by increasing the concentration of tragacanth (TG) and citric acid (CA) with an increment in floating time. The stearic acid (SA) has been used to decrease the lag time because a decrease in density of system was observed. The kinetic analysis showed that the optimized formulation (S4F3) followed zero-order kinetics and power law was found to be best fitted due to its minimum lag time and maximum floating ability. The resemblance of observed and predicted values indicated the validity of derived equations for evaluating the effect of independent variables while kinetic study demonstrated that the applied models are feasible for evaluating and developing float for RNT.
\end{abstract}

\section{Introduction}

The control drug delivery has been a critical zone of current research to upgrade the bioavailability of the drug. With phenomenal progress in medical engineering and material design, novel materials have been exploited for the improvement of drug delivery systems (DDS). Both natural and engineered macromolecules have been extensively utilized as a part of controlled drug delivery to amplify the bioadequacy of the drug and to enhance the patient compliance. A few strategies are being utilized for effective plan of a GRDDS to improve the GRT for most extreme assimilation in upper part of gastric system such as floating DDS, low density system (LDS), bioadhesive, superporous hydrogel, and magnetic system. The floating drug delivery is most broadly utilized among these methods [1-3]. The float formulation is an efficient approach to extend the residence time in stomach to increase the absorption of less soluble or less stable drugs in digestive system. This system is hydrodynamically welladjusted having lesser bulk density than GI (gastrointestinal) fluid. As a result system remains floating in the stomach without influencing other gastric functions and hence drug discharges out from float gradually at the coveted rate with least variance in blood plasma. The controlled drug delivery system (CDDS) has significant advantage, for example, patient compliance, simple administration, and flexible dosage forms $[4,5]$. Psyllium husk and dried seed layer of Plantago ovata have several pharmaceutical and therapeutic applications. Psyllium husk forms a clear transparent gel on absorbing water which is used as a food supplement [6]. Psyllium hydrogel (HG) comprises both dissolvable and insoluble reswellable polysaccharides. Psyllium husk forms three-dimensional structures in aqueous medium because of its gel forming ability $[7,8]$. The HG was utilized for float formation due to absence of toxic impurities, potential biocompatibility and ease of extraction, biodegradability, and aversion of gastric bothering by forming a coat around the gastric aggravation. In addition, it has many pharmaceutical applications and has been used in the treatment of numerous chronic infections [9-11]. Ranitidine is used for the 
treatment of Zollinger-Ellison Syndrome, gastroesophageal reflux, duodenal ulcers, gastric ulcer, and duodenal ulcer. The suggested dose of ranitidine for gastroesophageal reflux illness is $150 \mathrm{mg}$ twice a day; however, for erosive esophagitis same dose is four times a day or much more [12]. Studies have demonstrated that patient's compliances are antagonistically influenced by increase in number of doses. In this way sustained release would be more profitable in decreasing its frequency for compelling results $[13,14]$. The gastric residence time is essential for the drugs which are primarily absorbed through stomach or unstable at higher $\mathrm{pH}$. In this way, the controlled drug release in particular area of gastric tract offers different advantages like enhanced bioavailability and remedial viability [15].

The objective of this study was to prepare ranitidine floats of controlled drug delivery because of its low bioavailability (half) and short organic half-life (2-3 h) [16]. In the present premises, the RNT floats were composed of fractions disengaged from Psyllium husk gel and studied for their gastroretentive profile. The regression analysis was utilized to optimize the formulations; similarity $\left(f_{2}\right)$ and difference factors $(f 1)$ were used to look at the drug release profiles of all husk fractions with standard tablet accessible in the market. Distinctive kinetic models were connected, for example, zero order, first order, Higuchi model, Power law, and H-Crowell cube root law, to study the drug release rate and all these results demonstrate that the applied methods were sufficient for designing sustained release floats of RNT having better therapeutic and clinical outcomes.

\section{Materials and Methods}

Ranitidine (RNT) was provided by Ferozsons Laboratories Limited, Pakistan, as a gift. All other chemicals and solvents were purchased from Sigma Aldrich, Pakistan. All chemicals were of AR grade and used without further purification.

2.1. Isolation of Hydrogel. Psyllium husk (10 g) was immersed in excess distilled water $(2 \mathrm{~L})$ and kept overnight. After complete swelling, $\mathrm{NaOH}(0.4 \mathrm{M})$ solution was added to swelled husk with continuous stirring. The solution was filtered with muslin cloth to separate insoluble impurities. The glacial acetic acid was added gradually with stirring to filtered solution. The gel was decanted off and dried after complete dialysis by distilled water. For isolation of different fractions, the dried gel was again swelled in distilled water and treated with different solvents, for example, acetone, methanol, ethanol, and chloroform. Different fractions in different concentrations were again coagulated using the said solvents. After separation, these fractions were dialyzed thoroughly with distilled water to remove separating solvents. The purified gels were dried and ground to fine powder. The powdered gel was dissolved in drug solution. After absorbing the drug, whole mass was dried again. The dried mass was ground, mixed with excipients, and sprayed with isopropyl alcohol $\left({ }^{i} \mathrm{PrOH}\right)$ and then compressed to form floats. The separation of different fractions is shown in Figure 1.

\subsection{Characterization of $E N a$}

2.2.1. Elemental Analysis. CHNS analyzer was used to find the amount of $\mathrm{N}$ and $\mathrm{C}$ in given sample. The elemental analysis for each sample was performed in triplicate.

2.2.2. Thermal Analysis (TA). TA of isolated samples was carried out under $\mathrm{N}_{2}$ atmosphere at multiple heating rate (10, 15 , and $20^{\circ} \mathrm{C}$ ) using Broido's method and activation energy $\left(E_{a}\right)$ was calculated from the slope of line by least square methods:

$$
\log \left(\frac{1}{y}\right)=-\left(\frac{E_{a}}{R}\right)\left(\frac{1}{T}\right)+\text { constant, }
$$

where $T$ is the temperature in Kelvin and $R$ is general gas constant having value $8.31 \mathrm{JK}^{-1} \mathrm{~mol}^{-1}, y$ is ratio of difference in mass before and after heating $=\left(m_{t}-m_{f}\right) /\left(m_{0}-m_{f}\right)$, where $m_{t}$ is weight of polymer at temperature $T, m_{0}$ is the mass at initial temperature, and $m_{f}$ is the mass at the final temperature of particular decomposition stage, so Broido's equation can be represented as $E_{a}=-($ slope $\times 8.314)$. The data was analyzed (TA Instruments, USA) using Universal Analysis 2000 software, version 4.2E, and MS Excel ${ }^{\circledR} 2007$.

2.2.3. Gel Permeation Chromatography (GPC). GPC analysis was carried out with Agilent 1200 Series GPC-SEC System using pullulan and dextran as standards. The system was equipped with 2 columns and dimethyl sulphide was used as eluent with flow rate of $0.5 \mathrm{~mL} \mathrm{~min}^{-1}$ at $70^{\circ} \mathrm{C}$ using injections about $50 \mu \mathrm{L}$.

2.2.4. Fourier Transform-Infrared Spectroscopy. The absorption bands in FT-IR spectra of ENa were noted to compare with earlier work for same type of materials [17].

2.2.5. Scanning Electron Microscopy (SEM). Pellets of ENa fraction were prepared at 3000 psi pressure using hydraulic press. The pellets were mounted with the help of silver paint on aluminum stubs and subsequently were coated with gold. The SEM images were taken at different magnification using JEOL, JSM-6480 LV, Japan, at $10 \mathrm{kV}$.

2.2.6. Determination of Water Retention Value (WRV). The water retention was calculated by centrifugation method. About $1.0 \mathrm{~g}$ dried gel was placed in a beaker containing $100 \mathrm{~mL}$ distilled water at $30^{\circ} \mathrm{C}$ for $3 \mathrm{~h}$ for complete swelling. The swelled material was filled in 4 fritted glass tubes containing pores at the bottom. The tubes were centrifuged at $2500 \mathrm{rpm}$ for $40 \mathrm{~min}$ to remove the entrapped water. After centrifugation, sample material was dried in an oven at $60^{\circ} \mathrm{C}$ for complete dehydration. WRV\% was calculated as follows:

$$
\operatorname{WRV}(\%)=\frac{\left(m_{w}-m_{d}\right)}{m_{d}} \times 100,
$$

where $m_{w}$ is mass of sample (wet state) and $m_{d}$ is mass of sample (dry state). 


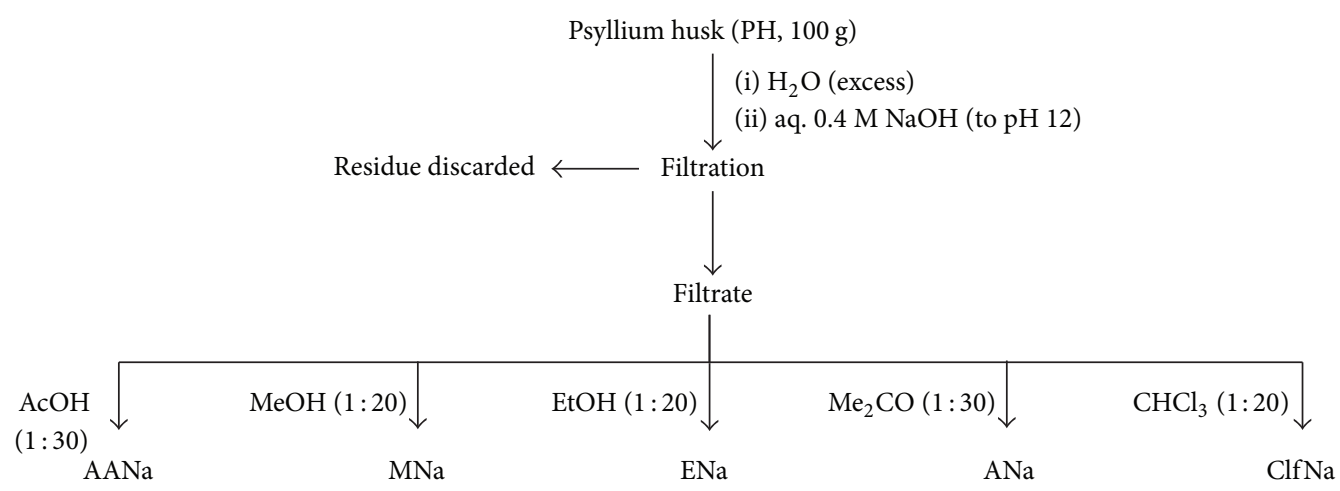

Acetic acid $=\mathrm{AcOH}$, methanol $=\mathrm{MeOH}$, ethanol $=\mathrm{EtOH}$, acetone $=\mathrm{Me}_{2} \mathrm{CO}$, chloroform $=\mathrm{CHCl}_{3}$

Gel extracted with $\mathrm{NaOH}$ and $\left[\mathrm{AcOH}(\mathrm{AANa}), \mathrm{MeOH}(\mathrm{MNa}), \mathrm{EtOH}(\mathrm{ENa}), \mathrm{Me}_{2} \mathrm{CO}(\mathrm{ANa}),\left(\mathrm{CHCl}_{3}(\mathrm{ClfNa})\right]\right.$

FIGURE 1: Separation of different fractions of husk gel.

TABLE 1: Formulations design for RNT floats (drug $120 \mathrm{mg}$ ).

\begin{tabular}{|c|c|c|c|c|c|}
\hline Batches & Materials (mg) & Low $(-1)$ & Medium (0) & High (+1) & Constant $^{*}$ \\
\hline \multirow{2}{*}{1 st } & $\mathrm{ENa}$ & 100 & 150 & 200 & $\mathrm{NaHCO}_{3}=10$ \\
\hline & SA & 30 & 60 & 90 & $\mathrm{CA}=10$ \\
\hline \multirow{2}{*}{ 2nd } & $\mathrm{ENa}$ & 100 & 150 & 200 & $\mathrm{NaHCO}_{3}=10$ \\
\hline & Tcanth & 30 & 60 & 90 & $\mathrm{CA}=10$ \\
\hline \multirow{2}{*}{$3 \mathrm{rd}$} & $\mathrm{ENa}$ & 100 & 150 & 200 & $\mathrm{NaHCO}_{3}=10$ \\
\hline & LSG & 30 & 60 & 90 & $\mathrm{CA}=10$ \\
\hline \multirow{2}{*}{4 th } & $\mathrm{ENa}$ & 100 & 150 & 200 & $\mathrm{NaHCO}_{3}=15$ \\
\hline & PSG & 30 & 60 & 90 & $\mathrm{CA}=10$ \\
\hline
\end{tabular}

LSG = linseed gel; PSG = psyllium seed gel; ${ }^{*} \mathrm{CHCl}_{3}={ }^{i} \mathrm{PrOH}=2 \mathrm{~mL} ; \mathrm{TG}=$ tragacanth gel; SA = stearic acid; CA = citric acid; HPMC: hydroxy propyl methyl cellulose; $\mathrm{Mg}$ stearate $=5 \mathrm{~g}$ to each float.

The drug content, friability, and stability of floats were measured as per set criteria by taking 10 floats and after grinding concentration of solution was noted by dissolving in water. The friability was checked by the formula

$$
\text { Friability }=\frac{(\text { Initial mass of sample })}{(\text { Final mass of sample })} \times 100 .
$$

2.3. Preparation of Floats. For each float, a specific quantity of hydrogel along with excipients as per factorial design was taken and mixed geometrically in plastic bag. The mixture was passed through sieve of mesh size 16 and then poured into drug solution. The drug loaded mixture was separated, dried, and ground to fine powder and then sprayed with ${ }^{i} \mathrm{PrOH}(\sim 2 \mathrm{~mL})$ with rapid geometric mixing. The floats were prepared by punch machine having punch size $10 \times 1.5 \mathrm{~mm}$ by direct compression technique with small amount of $\mathrm{Mg}$ stearate as lubricant.

2.4. Preparation of Factorial Formulations. Floats were prepared as per factorial model $\left(3^{2}\right)$ as described in Table 1. Four different batches were designed by varying the concentrations of ENa and SA, ENa, LSG, and PSG as low, medium, and high as shown in Table 1.
2.5. Dissolution Study. All DR profiles were studied using USP paddle dissolution apparatus II at $37^{\circ} \mathrm{C} \pm 0.1^{\circ} \mathrm{C}$ and $50 \mathrm{rpm}$ in buffer solutions of $\mathrm{pH} 1.2(900 \mathrm{~mL}$ in each beaker). About $5 \mathrm{~mL}$ sample was taken with syringe. After suitable dilution, sample was analyzed at $\lambda_{\max } 314 \mathrm{~nm}$. After removal of sample, same amount of dissolution medium at same temperature was added to keep the total volume $900 \mathrm{~mL}$. Accumulative DR percentage was calculated from a standard curve. A calibration graph for RNT was plotted against its concentration (ppm) in buffer solution $(\mathrm{pH} \mathrm{1.2)}$ and was regressed into linear line.

2.6. In Vitro Buoyancy. The floating lag time (LT) and the total floating time (TFT) were determined for each float in USP dissolution apparatus II containing simulated gastric fluid at $\mathrm{pH} 1.2$ at $37 \pm 0.5^{\circ} \mathrm{C}$. The lag time and TFT for each dosage form were also calculated.

2.7. Similarity and Difference Factors. According to Moore and Flanner, similarity factor $\left(f_{2}\right)$ is, actually, measurement of similarity in the percent dissolution of drug of sample profile and control profile.

$$
f_{2}=50 \times \log \left[\left\{1+\left(\frac{1}{n}\right) \sum\left|R_{t}^{2}-T_{t}^{2}\right|\right\}^{1 / 2} \times 100\right] .
$$


TABLE 2: Thermal parameters of ENa gel fractions.

\begin{tabular}{|c|c|c|c|c|c|c|c|c|c|c|}
\hline $\begin{array}{l}\text { Sample } \\
\text { code }\end{array}$ & $\begin{array}{l}\text { Temp. } \\
\text { range } \\
\left({ }^{\circ} \mathrm{C}\right)\end{array}$ & $\begin{array}{c}\text { Mass } \\
\text { loss } \\
(\%)\end{array}$ & $\begin{array}{c}E_{a} \\
\mathrm{~kJ} \mathrm{~mol}^{-1}\end{array}$ & $\begin{array}{c}\Delta H^{*} \\
\mathrm{~kJ} \mathrm{~mol}^{-1}\end{array}$ & $\begin{array}{c}\Delta S^{*} \\
\mathrm{JK}^{-1} \mathrm{~mol}^{-1}\end{array}$ & $\begin{array}{c}\Delta G^{*} \\
\mathrm{~kJ} \mathrm{~mol}^{-1}\end{array}$ & $\ln A$ & $\begin{array}{c}\text { IPDT } \\
\left({ }^{\circ} \mathrm{C}\right)\end{array}$ & ITS & $\begin{array}{c}\text { Mass at } \\
600^{\circ} \mathrm{C} \\
(\%)\end{array}$ \\
\hline $\mathrm{ENa}$ & $223-315$ & 49.24 & 146.68 & 139.76 & -51.47 & 169.66 & 22.82 & 289.42 & 0.46 & 0.983 \\
\hline
\end{tabular}

The dissolution profiles will be similar to control (standard) profile when $f_{2}$ value is $>50$ where $f 1$ measures percentage difference between test and control dissolution profile. Its standard values are 0 to 15 for no difference.

2.8. Kinetic Study. In vitro DR data was studied by using different kinetic models to find the mechanism and drug release rate.

2.9. Statistical Analysis. The drug release percentage at $2 \mathrm{~h}$, $5 \mathrm{~h}$, and $10 \mathrm{~h}$ was statistically analyzed by using the DESIGN EXPERT 7.1.5.0 (STAT-EASE) demo version software. The linear regression analysis (LRA) was applied to all formulations of each batch and an equation was derived for fixed time interval to find the effect of independent variables.

\section{Results and Discussion}

3.1. Extraction of Hydrogel. The ENa fraction extracted by alkali-ethanol method was found to be most suitable due to its minimum lag time as compared to other fractions as matrix. In present study, $\mathrm{NaOH}$ solution was used for dissolution of gel. Although this is a chemical method it is more economical for production of pure gel. The ion dipoles interaction between $\mathrm{NaOH}$ and hydroxyl $(-\mathrm{OH})$ groups results in cleavage of molecular $\mathrm{H}$-bonding among the hydrogel layers and decreases the viscosity of solution; hence filtration becomes easier. The separated gels were dialyzed with distilled water and washed until the $\mathrm{pH}$ was restored to 7. The purified transparent gel was dried and its yield was found to be $30 \%$ relative to weight of husk. The extracted material was found to be good DR retardant and suitable for floats due to its low density.

\subsection{Characterization of ENa}

3.2.1. Elemental Analysis. The elemental analysis shows that $\mathrm{ENa}$ is free of any nitrogenous matter (proteins). Even with performing the analysis in triplicate no evidence of nitrogen was found in all samples. The percentage of $\mathrm{C}$ and $\mathrm{H}$ was found to be $40.2 \%$ and $6.5 \%$ against $45.0 \%$ and $6.0 \%$, respectively, as observed in other natural polysaccharides (pullulan, etc.) [17].

3.2.2. Thermal Analysis. The ENa was studied by TGA and DSC from ambient temperature to $600^{\circ} \mathrm{C}$. The TGA showed an endothermic weight loss about $10 \%$ up to $200^{\circ} \mathrm{C}$, which was attributed to the loss of absorbed moisture. The weight loss of $\sim 45 \%$ was observed in range $226-326^{\circ} \mathrm{C}$, which was due to degradation of ENa structure. This step was
TABLE 3: GPC parameters of ENa.

\begin{tabular}{lc}
\hline Parameters & ENa \\
\hline$M_{n}\left(\mathrm{~g} \mathrm{~mol}^{-1}\right)$ & $3.443 \times 10^{3}$ \\
$M_{w}\left(\mathrm{~g} \mathrm{~mol}^{-1}\right)$ & $1.344 \times 10^{4}$ \\
$M_{z}\left(\mathrm{~g} \mathrm{~mol}^{-1}\right)$ & $2.967 \times 10^{4}$ \\
$M_{p}\left(\mathrm{~g} \mathrm{~mol}^{-1}\right)$ & $8.273 \times 10^{3}$ \\
$V_{p}\left(\mathrm{~cm}^{3}\right)$ & 7.497 \\
PDI & 3.724 \\
\hline
\end{tabular}

exothermic in nature. The second weight loss of $\sim 24 \%$ was observed at temperature $452-563^{\circ} \mathrm{C}$ due to complete degradation of ENa leaving behind a carbon rich residue. Glass transition temperature $\left(T_{g}\right)$ could not be observed in the experimental range due to presence of carbon. The average $E_{a}$ value calculated by Broido's method was $134 \mathrm{~kJ} \mathrm{~mol}^{-1}$ using $10^{\circ} \mathrm{C} \mathrm{min}^{-1}$ and thermogram was comparable to those of other commercially available polysaccharides [18].

An overall thermal stability of ENa along with other fractions was assessed by integral procedural decomposition temperature (IPDT) and comprehensive index of thermal stability (ITS) values by Doyle's method. The IPDT and ITS value were found to be $289^{\circ} \mathrm{C}$ and 0.46 , respectively. These values indicate that ENa has good thermal stability $[19,20]$. The apparent $E_{a}$ values for major stage of decomposition were also calculated using Flynn-Wall-Ozawa (FWO) method. The $E_{a}$ values varied greatly with $\alpha$ indicating a multistep degradation. The average activation energies by FWO method are given in Table 2 and Figure 2.

3.2.3. Gel Permeation Chromatography (GPC). GPC was used to determine molar mass distribution $M_{n}$ (numberaverage), $M_{w}$ (weight-average), $M_{z}$ (average molar masses), and polydispersity index (PDI) which is the ratio of $M_{w} / M_{n}$. The PDI value of ENa was to be found as 3.724 which indicates that ENa is polydispersed in nature Table 3.

3.2.4. Fourier Transform-Infrared Spectroscopy (FT-IR). The absorption bands in FT-IR spectra (Figure 3) were assigned taking two fractions for comparison. The absorbance at $3323.35 \mathrm{~cm}^{-1}$ was due to $-\mathrm{OH}$ stretching (broad band). The absorbances at $1251.80-1328.86 \mathrm{~cm}^{-1}$ were due to deformation caused by absorbed water. A sharp band at $1012-1047.5 \mathrm{~cm}^{-1}$ was due to beta-glycosidic bond. The absorbances at 651-690.62 and 528-549 $\mathrm{cm}^{-1}$ were observed due to polymer backbone. 

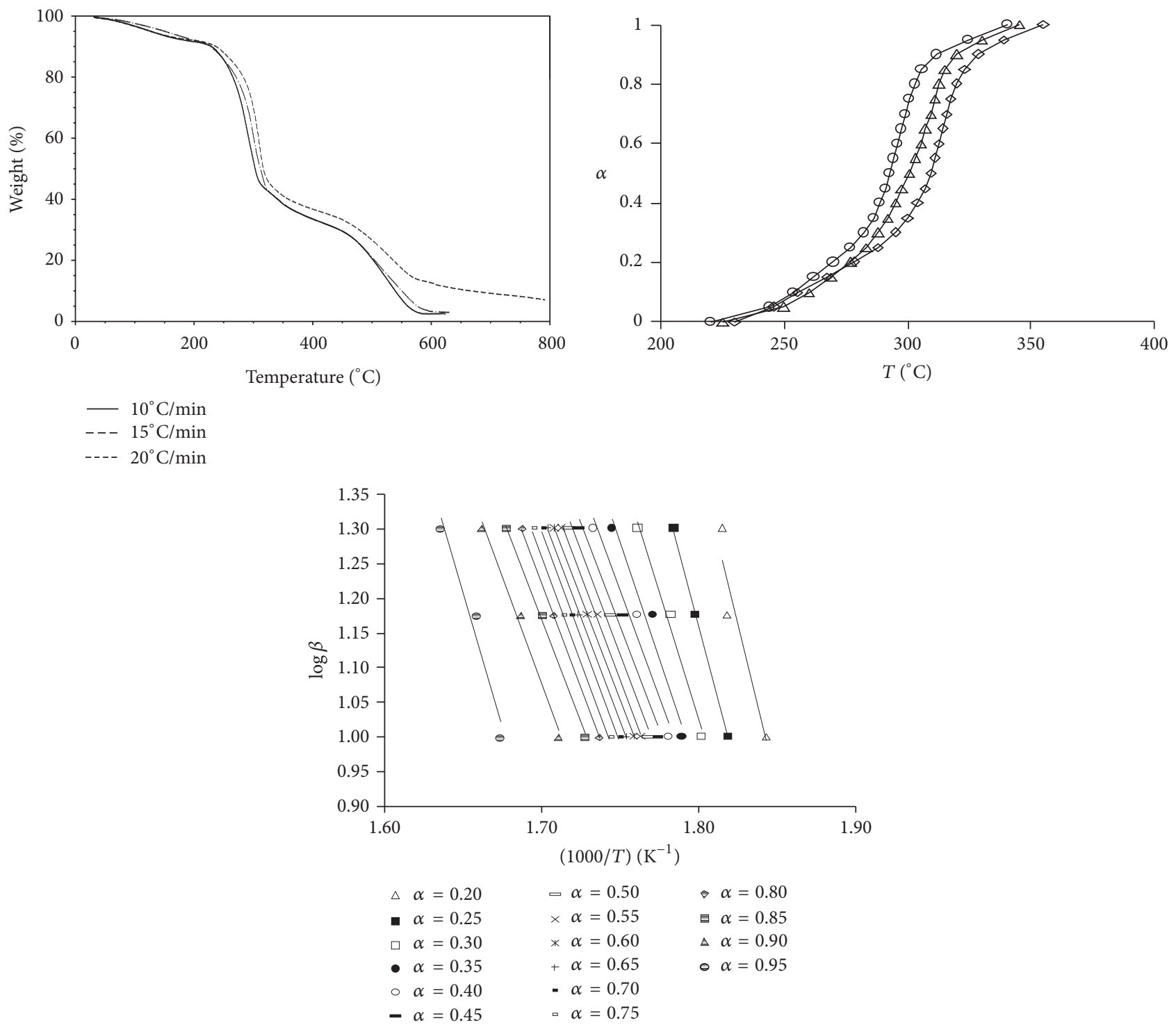

FiguRE 2: Thermogravimetric curves of ENa (L) and representative $\alpha$-T curve and $\log \beta(\mathrm{R})$ for $\mathrm{ENa}(\mathrm{R})$.

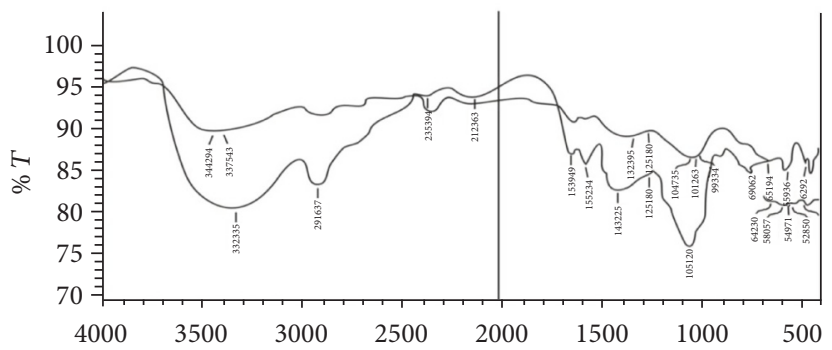

FigURE 3: Representative FT-IR graphs of ENa and AANa (comparison).

3.2.5. Surface Morphology of ENa. Scanning electron microscopy (SEM) of ENa (Figure 4) indicates that its surface is highly rough, which could provide more surface area to adhere with drug for adsorption reported in Iqbal et al. [21].

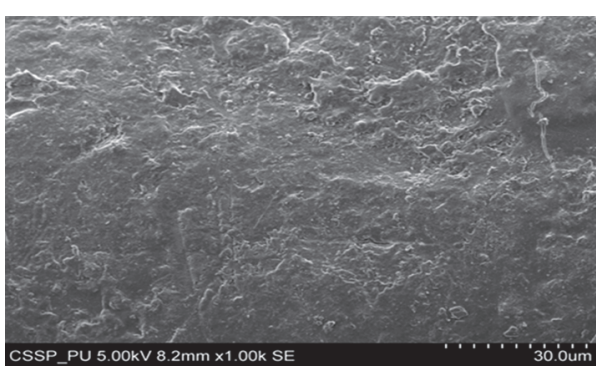

FIGURE 4: Scanning electron microscopy of ENa.

3.2.6. Water Retention Value (WRV). The WRV was found to be $7000 \%$ to $7500 \%$ to its original volume. The $\mathrm{H}_{2} \mathrm{O}$ holding capacity decreased on exposure to atmosphere with the passage of time; therefore WRV is not permanent. Being 
TABLE 4: Lag time (LT) of all batches.

\begin{tabular}{|c|c|c|c|c|c|c|c|c|c|}
\hline RNT & $\mathrm{MNa}$ & $\mathrm{ENa}$ & AANa & Clf Na & $\mathrm{ANa}$ & Husk & $C_{\text {std }}$ & & \\
\hline LT (min) & 22 & 19 & 27 & 30 & 26 & 24 & 12 & & \\
\hline Batch-S1 & F1 & F2 & F3 & $\mathrm{F} 4$ & F5 & F6 & F7 & F8 & F9 \\
\hline LT (sec) & 120 & 100 & 45 & 165 & 145 & 130 & 80 & 70 & 60 \\
\hline Batch-S2 & $\mathrm{F} 1$ & $\mathrm{~F} 2$ & F3 & $\mathrm{F} 4$ & F5 & F6 & F7 & F8 & F9 \\
\hline LT (sec) & 80 & 125 & 150 & 180 & 200 & 256 & 300 & 325 & 375 \\
\hline Batch-S3 & $\mathrm{F} 1$ & $\mathrm{~F} 2$ & F3 & $\mathrm{F} 4$ & F5 & F6 & F7 & F8 & F9 \\
\hline LT (sec) & 100 & 150 & 195 & 170 & 225 & 245 & 260 & 285 & 295 \\
\hline Batch-S4 & $\mathrm{F} 1$ & $\mathrm{~F} 2$ & F3 & $\mathrm{F} 4$ & $\mathrm{~F} 4$ & F6 & F7 & F8 & F9 \\
\hline $\mathrm{LT}(\min )$ & 07 & 05 & 03 & 08 & 06 & 08 & 11 & 14 & 19 \\
\hline
\end{tabular}

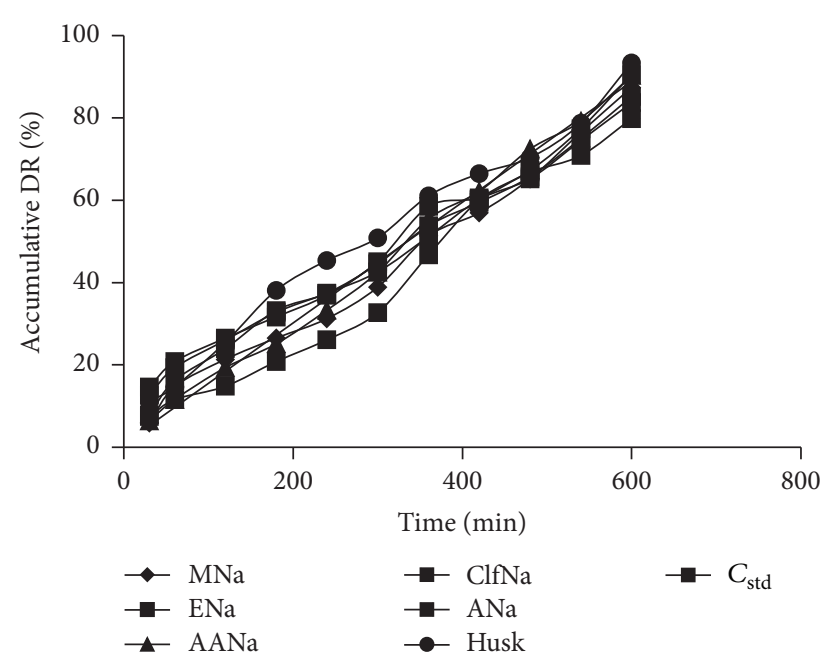

Figure 5: Drug release profiles of RNT from isolated fractions.

reswellable, it can be reused after drying. Being highly hydrophilic, it is considered as hydrogel. All formulations were found to be uniform and their drug content ranged from 97.37 to 100.34 .

3.2.7. Dissolution Study and Float Formulations. The concentration of drug was calculated using the equation $y=0.002 \times$ concentration +0.003 .

From above equation and Figure 5 it was found that DR\% from all fractions ranged from 83.5 to $90.2 \%$ where the DR by husk and marketed tablets $\left(C_{\text {std }}\right)$ was found to be 93.3 and $79.8 \%$, respectively. On studying the DR\% of different formulations, it was found that the DR was retarded notably by increasing the amount of husk gel but DR data indicates that the use of $\mathrm{HG}$ by itself as sustained release matrix is insufficient to achieve the CR (controlled release) profile, Figure 5. Therefore different excipients were used to accommodate balance in DR rates due to difference in swelling from Psyllium polysaccharide. ENa was selected as the main excipient (matrix) due to its better DR retarding ability. The DR\% of various batches was calculated at different time intervals and given in Table 4. The rate of swelling depends upon the amount of $\mathrm{H}_{2} \mathrm{O}$ taken up by the polymer which depends upon nature of added excipients. The hardness of all floats formulations was in the range
$6.0-8.0 \mathrm{~kg} / \mathrm{cm}^{2}$. The percentage friability of all the floats was not found to be more than $0.7 \%$. To increase the wetting ability and decrease the lag time, $\mathrm{NaHCO}_{3}$ was added in the matrix, which produced $\mathrm{CO}_{2}$ on contact with simulated gastric fluid which was entrapped within the polymer and decreased the density of system. The drug release $\%$ of all formulations for $10 \mathrm{~h}$ are shown in Tables 6-9, which indicates that drug release rate depends upon nature and concentration of adding excipients and their effect was studied by regression analysis. By addition of TG, DR rate increased due to having soluble component. TG gum is actually a mixture of soluble component tragacanthin (30-40\%) and insoluble component bassorin (60-70\%). On addition of LSG, the DR rate was decreased due to its greater retarding ability and it was further decreased by addition of PSG. In order to increase the DR rate, concentration of $\mathrm{NaHCO}_{3}$ was increased in 4 th batch. So by the adjustment of variables, as recommended by regression analysis and formulation, S4F3 was found to better due to its minimum lag time and maximum floating ability with better sustainability (Figure 6).

TA data indicates that ENa is equally stable as other hydrogel, Table 2 . The DR\% of all fractions and designed formulations are shown in Table 6 and similarity and difference factors are shown in Table 7, which are major indicators to understand the formulation design. The kinetic study of some selected batches, Tables 6-9, indicates that as the $n$ value is greater than 0.45 , the DR behavior is trending towards nonFickian diffusion. In case of optimized formulation S4F3, the value of $n$ is 0.31 indicating that release mechanism is totally Fickian diffusion [22].

3.2.8. In Vitro Buoyancy. The total floating and lag time of all formulation were calculated, given in Table 4 , and minimum lag time and maximum floating time were detected in formulation S4F3. So this formulation was selected and found to be best one for floating DDS. The target of this study was to choose the formulations having maximum GRT with best bioavailability of drug. Among all the fractions, ENa has minimum lag time and maximum floating ability; therefore this fraction was chosen for designing other formulations.

3.2.9. Similarity and Difference Factors. Similarity and difference factors of all the formulations, using ENa reference matrix tablet as standard, (Table 5) indicate that all formulations which have $f_{2}$ factor greater than 50 resemble standard 

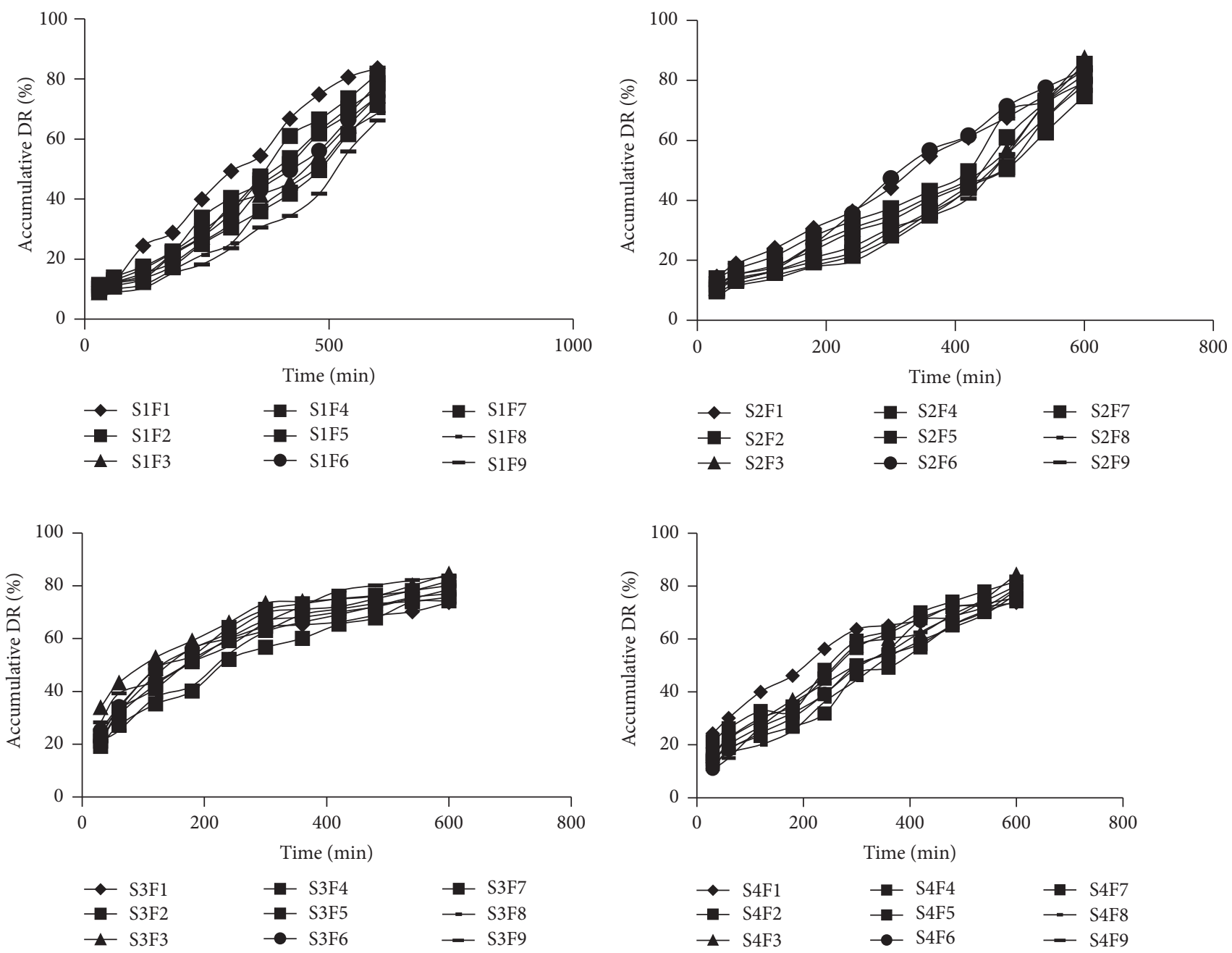

FIgURE 6: Drug release profiles of four batches (S1 to S4 each containing nine formulations).

TABLE 5: Similarity $\left(f_{2}\right)$ and difference factor $(f 1)$ for all batches.

\begin{tabular}{llccccccccc}
\hline RNT & & F1 & F2 & F3 & F4 & F5 & F6 & F7 & F8 & F9 \\
\hline \multirow{2}{*}{ S1 } & $f 1$ & 28.50 & 13.71 & 13.02 & 18.80 & 19.83 & 26.45 & 23.61 & 23.62 & 25.18 \\
& $f 2$ & 50.76 & 65.49 & 64.92 & 59.58 & 57.76 & 50.97 & 54.84 & 55.56 & 53.73 \\
\multirow{2}{*}{$C_{\text {std }}$} & $f 1$ & 13.02 & 13.67 & 20.77 & 23.33 & 29.98 & 36.26 & 32.51 & 32.52 & 34.21 \\
& $f 2$ & 62.93 & 64.22 & 55.95 & 52.51 & 44.82 & 40.19 & 45.33 & 43.95 & 42.10 \\
S2 & $f 1$ & 20.71 & 9.27 & 9.47 & 22.67 & 15.51 & 17.01 & 17.15 & 18.66 & 21.28 \\
& $f 2$ & 59.10 & 72.03 & 74.01 & 56.30 & 62.44 & 62.87 & 61.62 & 59.78 & 56.04 \\
& $f 1$ & 15.27 & 16.62 & 20.61 & 18.53 & 24.92 & 26.80 & 26.37 & 28.97 & 31.61 \\
$C_{\text {std }}$ & $f 2$ & 60.52 & 58.40 & 52.50 & 57.21 & 50.56 & 48.20 & 49.46 & 46.40 & 43.60 \\
& $f 1$ & 13.37 & 14.58 & 18.28 & 18.46 & 23.60 & 31.02 & 24.05 & 30.49 & 37.87 \\
\multirow{3}{*}{ S3 } & $f 2$ & 62.12 & 59.09 & 54.58 & 54.54 & 49.12 & 43.48 & 47.69 & 43.14 & 39.04 \\
& $f 1$ & 22.82 & 21.35 & 21.45 & 23.52 & 23.75 & 29.28 & 27.30 & 30.49 & 35.60 \\
\multirow{2}{*}{$C_{\text {std }}$} & $f 2$ & 52.63 & 54.08 & 53.64 & 52.17 & 49.91 & 45.03 & 47.37 & 43.89 & 40.36 \\
& $f 1$ & 44.14 & 17.58 & 10.30 & 33.38 & 23.43 & 8.92 & 14.07 & 07.08 & 07.81 \\
S4 & $f 2$ & 44.25 & 62.44 & 71.55 & 50.21 & 57.92 & 74.99 & 65.19 & 75.54 & 76.34 \\
& $f 1$ & 18.34 & 15.79 & 20.19 & 14.87 & 15.45 & 25.78 & 22.84 & 24.25 & 27.39 \\
\multirow{2}{*}{$C_{\text {std }}$} & $f 2$ & 55.76 & 60.88 & 55.18 & 60.65 & 60.57 & 49.01 & 52.45 & 50.38 & 47.30 \\
\hline
\end{tabular}


TABLE 6: Kinetic study of DR from polymer matrix.

\begin{tabular}{lcccccccccccc}
\hline \multirow{2}{*}{ RNT } & \multirow{2}{*}{$\mathrm{S}_{10 \mathrm{~h}}$} & \multicolumn{2}{c}{ Zero order } & \multicolumn{2}{c}{ First order } & \multicolumn{2}{c}{ Higuchi } & \multicolumn{2}{c}{ H-Crowell } & \multicolumn{3}{c}{ Power law } \\
& & $k_{o}$ & $R^{2}$ & $k_{1}$ & $R^{2}$ & $k_{\mathrm{H}}$ & $R^{2}$ & $k_{\mathrm{HC}}$ & $R^{2}$ & $k_{P}$ & $R^{2}$ & $n$ \\
\hline $\mathrm{MNa}$ & 86.8 & 0.133 & 0.918 & -0.004 & 0.985 & 3.922 & 0.968 & -0.042 & 0.907 & 0.024 & 0.976 & 0.577 \\
$\mathrm{ENa}$ & 84.5 & 0.123 & 0.862 & -0.004 & 0.957 & 3.659 & 0.962 & -0.039 & 0.773 & 0.021 & 0.951 & 0.561 \\
$\mathrm{AANa}$ & 91.2 & 0.095 & 0.852 & -0.004 & 0.967 & 3.061 & 0.942 & -0.032 & 0.851 & 0.071 & 0.922 & 0.389 \\
$\mathrm{ANa}$ & 82.7 & 0.133 & 0.973 & -0.004 & 0.977 & 3.775 & 0.958 & -0.043 & 0.982 & 0.022 & 0.972 & 0.575 \\
$\mathrm{ClfNa}$ & 84.1 & 0.128 & 0.982 & -0.004 & 0.965 & 4.231 & 0.981 & -0.045 & 0.987 & 0.006 & 0.977 & 0.789 \\
$\mathrm{H}$ & 95.3 & 0.118 & 0.918 & -0.004 & 0.828 & 3.272 & 0.885 & -0.033 & 0.924 & 0.062 & 0.887 & 0.423 \\
$\mathrm{C}_{\text {std }}$ & 82.8 & 0.113 & 0.952 & -0.004 & 0.918 & 3.241 & 0.985 & -0.035 & 0.942 & 0.091 & 0.972 & 0.357 \\
\hline
\end{tabular}

TABLE 7: DR study for 1st batch matrix tablets.

\begin{tabular}{|c|c|c|c|c|c|c|c|c|c|c|c|c|}
\hline \multirow{2}{*}{ RNT (S1) } & \multirow{2}{*}{$\mathrm{S}_{10 \mathrm{~h}}$} & \multicolumn{2}{|c|}{ Zero order } & \multicolumn{2}{|c|}{ First order } & \multicolumn{2}{|c|}{ Higuchi } & \multicolumn{2}{|c|}{ H-Crowell } & \multicolumn{3}{|c|}{ Power law } \\
\hline & & $k_{o}$ & $R^{2}$ & $k_{1}$ & $R^{2}$ & $k_{\mathrm{H}}$ & $R^{2}$ & $k_{\mathrm{HC}}$ & $R^{2}$ & $k_{P}$ & $R^{2}$ & $n$ \\
\hline $\mathrm{F} 1$ & 83.5 & 0.134 & 0.989 & -0.002 & 0.958 & 4.091 & 0.969 & -0.044 & 0.989 & 0.003 & 0.978 & 0.832 \\
\hline $\mathrm{F} 2$ & 78.4 & 0.132 & 0.882 & -0.003 & 0.949 & 4.295 & 0.953 & -0.044 & 0.992 & 0.005 & 0.962 & 0.829 \\
\hline F3 & 74.4 & 0.132 & 0.857 & -0.003 & 0.946 & 4.278 & 0.944 & -0.044 & 0.857 & 0.003 & 0.953 & 0.877 \\
\hline $\mathrm{F} 4$ & 81.8 & 0.128 & 0.988 & -0.002 & 0.987 & 3.946 & 0.989 & -0.042 & 0.988 & 0.003 & 0.995 & 0.852 \\
\hline F5 & 76.8 & 0.124 & 0.994 & -0.002 & 0.96 & 3.777 & 0.963 & -0.041 & 0.994 & 0.003 & 0.989 & 0.869 \\
\hline F6 & 74.3 & 0.122 & 0.986 & -0.002 & 0.938 & 3.652 & 0.928 & -0.042 & 0.986 & 0.004 & 0.978 & 0.858 \\
\hline F7 & 71.7 & 0.129 & 0.968 & -0.002 & 0.932 & 3.864 & 0.912 & -0.043 & 0.968 & 0.002 & 0.956 & 0.912 \\
\hline F8 & 68.4 & 0.118 & 0.962 & -0.002 & 0.88 & 3.492 & 0.879 & -0.039 & 0.962 & 0.003 & 0.956 & 0.849 \\
\hline F9 & 66.0 & 0.111 & 0.941 & -0.001 & 0.841 & 3.252 & 0.852 & -0.037 & 0.941 & 0.004 & 0.941 & 0.865 \\
\hline
\end{tabular}

TABLE 8: DR study for 2nd batch matrix tablets.

\begin{tabular}{|c|c|c|c|c|c|c|c|c|c|c|c|c|}
\hline \multirow{2}{*}{ RNT (S2) } & \multirow{2}{*}{$\mathrm{S}_{10 \mathrm{~h}}$} & \multicolumn{2}{|c|}{ Zero order } & \multicolumn{2}{|c|}{ First order } & \multicolumn{2}{|c|}{ Higuchi } & \multicolumn{2}{|c|}{ H-Crowell } & \multicolumn{3}{|c|}{ Power law } \\
\hline & & $k_{o}$ & $R^{2}$ & $k_{1}$ & $R^{2}$ & $k_{\mathrm{H}}$ & $R^{2}$ & $k_{\mathrm{HC}}$ & $R^{2}$ & $k_{P}$ & $R^{2}$ & $n$ \\
\hline F1 & 83.5 & 0.135 & 0.955 & -0.0025 & 0.982 & 3.913 & 0.982 & -0.043 & 0.945 & 0.022 & 0.985 & 0.554 \\
\hline $\mathrm{F} 2$ & 85.2 & 0.107 & 0.969 & -0.0027 & 0.975 & 3.351 & 0.995 & -0.035 & 0.969 & 0.043 & 0.985 & 0.470 \\
\hline F3 & 87.6 & 0.103 & 0.904 & -0.002 & 0.933 & 3.269 & 0.969 & -0.032 & 0.903 & 0.033 & 0.973 & 0.482 \\
\hline $\mathrm{F} 4$ & 78.4 & 0.086 & 0.755 & -0.002 & 0.897 & 2.849 & 0.882 & -0.027 & 0.766 & 0.482 & 0.876 & 0.482 \\
\hline F5 & 81.8 & 0.102 & 0.951 & -0.002 & 0.975 & 3.176 & 0.988 & -0.036 & 0.944 & 0.033 & 0.962 & 0.512 \\
\hline F6 & 83.4 & 0.091 & 0.853 & -0.002 & 0.927 & 2.913 & 0.927 & -0.034 & 0.842 & 0.043 & 0.888 & 0.450 \\
\hline F7 & 74.7 & 0.088 & 0.793 & -0.002 & 0.823 & 2.853 & 0.878 & -0.027 & 0.793 & 0.044 & 0.965 & 0.464 \\
\hline F8 & 79.2 & 0.104 & 0.881 & -0.003 & 0.985 & 3.326 & 0.964 & -0.036 & 0.872 & 0.054 & 0.966 & 0.446 \\
\hline F9 & 80.1 & 0.095 & 0.736 & -0.003 & 0.932 & 3.154 & 0.866 & -0.034 & 0.744 & 0.056 & 0.824 & 0.457 \\
\hline
\end{tabular}

tablets with respect to the release rate but the formulation having lesser $f_{2}$ than 50 deviate from resemblance. Similarly the formulations having $f 10-15$ resemble $C_{\text {std }}$ but deviation from these values indicates that their release pattern is somewhat different from reference formulation.

3.2.10. Kinetic Study. The DR data was evaluated by using different kinetic models. By applying Korsmeyer and Peppas equation to DR data of different fractions of Psyllium husk, the diffusion coefficient $(n)$ was found in the range from 0.356 to $0.799 \pm 0.01$ with $\mathrm{DR} \%$ from 81.8 to 94.3 in $10 \mathrm{~h}$. These results indicate that the release mechanism was
non-Fickian diffusion as compared to $C_{\text {std }}$, Table 5. Therefore new formulations were designed to find the desired formulation, Tables 6-9.

3.2.11. Regression Analysis. The equations (see (5)-(16)) derived by SRA indicate that each factor has either positive or negative sign. The negative sign indicates that its concentration must be decreased while having positive sign indicates that concentration must be increased to achieve desired DR profile. The following notations were used for abbreviation for different variables $X_{1}=A, X_{2}=B, X_{1} X_{2}=C, X_{1}{ }^{2}=D$, $X_{2}^{2}=E$. 
TABLE 9: DR study for 4th batch matrix tablets.

\begin{tabular}{|c|c|c|c|c|c|c|c|c|c|c|c|c|}
\hline \multirow{2}{*}{ RNT (S4) } & \multirow{2}{*}{$\mathrm{S}_{10 \mathrm{~h}}$} & \multicolumn{2}{|c|}{ Zero order } & \multicolumn{2}{|c|}{ First order } & \multicolumn{2}{|c|}{ Higuchi } & \multicolumn{2}{|c|}{ H-Crowell } & \multicolumn{3}{|c|}{ Power law } \\
\hline & & $k_{o}$ & $R^{2}$ & $k_{1}$ & $R^{2}$ & $k_{\mathrm{H}}$ & $R^{2}$ & $k_{\mathrm{HC}}$ & $R^{2}$ & $k_{P}$ & $R^{2}$ & $n$ \\
\hline F1 & 73.7 & 0.100 & 0.855 & -0.002 & 0.956 & 3.265 & 0.952 & -0.033 & 0.855 & 0.033 & 0.948 & 0.516 \\
\hline $\mathrm{F} 2$ & 81.6 & 0.105 & 0.935 & -0.002 & 0.983 & 3.315 & 0.981 & -0.035 & 0.935 & 0.041 & 0.984 & 0.462 \\
\hline F3 & 85.5 & 0.084 & 0.962 & -0.002 & 0.989 & 2.517 & 0.981 & -0.028 & 0.962 & 0.051 & 0.975 & 0.313 \\
\hline F4 & 74.2 & 0.080 & 0.811 & -0.001 & 0.921 & 2.612 & 0.903 & -0.026 & 0.811 & 0.045 & 0.895 & 0.446 \\
\hline F5 & 77.5 & 0.097 & 0.924 & -0.002 & 0.928 & 3.091 & 0.974 & -0.032 & 0.924 & 0.038 & 0.969 & 0.479 \\
\hline F6 & 82.2 & 0.075 & 0.771 & -0.001 & 0.826 & 2.404 & 0.834 & -0.025 & 0.771 & 0.071 & 0.839 & 0.340 \\
\hline F7 & 74.2 & 0.089 & 0.958 & -0.001 & 0.972 & 2.783 & 0.991 & -0.029 & 0.959 & 0.051 & 0.976 & 0.410 \\
\hline F8 & 75.1 & 0.096 & 0.951 & -0.002 & 0.886 & 2.811 & 0.869 & -0.032 & 0.951 & 0.041 & 0.807 & 0.393 \\
\hline F9 & 79.4 & 0.092 & 0.986 & -0.002 & 0.935 & 2.763 & 0.937 & -0.031 & 0.986 & 0.051 & 0.891 & 0.377 \\
\hline
\end{tabular}

\subsubsection{1st Batch}

$$
\begin{aligned}
& \mathrm{S} 1=0.09729 t+0.028367 A-0.86738 B+0.001853 C \\
&- 0.00047 D+0.010767 E-15.65378 \\
&(\mathrm{CRC}=\left.0.903129, R^{2}=0.813737, \text { Adj. } R^{2}=0.757978, n=27\right) \\
& \mathrm{S}_{5 \mathrm{~h}}= 0.100789 t-0.02018 A-1.06322 B+0.003319 \mathrm{C} \\
&-0.00027 A+0.012404 B+24.3492 \\
&(\mathrm{CRC}=\left.0.969284, R^{2}=0.939511, \text { Adj. } R^{2}=0.931789, n=99\right) \\
& \mathrm{S} 1_{10 \mathrm{~h}}= 0.125672 t-0.0648 A-0.84731 B+0.002747 \mathrm{C} \\
&-0.00038 A+0.004249 B+22.84727 \\
&(\mathrm{CRC}=\left.0.992215, R^{2}=0.983514, \text { Adj. } R^{2}=0.982528, n=99\right) .
\end{aligned}
$$

In study, the SRA shows that effect of $B$ and $C$ is more significant while effect of $D$ is least effective (see (5)). After study it is found that effect of $B$ is most significant while effect of $A$ is negligible (see (6)) and after $10 \mathrm{~h}$ it was found that effect of $B$ and $C_{2}$ is significant while effect of $D, A$, and $E$ is negligible (see (7)).

The abbreviated kinetic study of 1st, $2 \mathrm{nd}$, and 4 th batch with nine formulations each has been discussed to identify the optimized formulation.

\subsubsection{2nd Batch}

$$
\begin{aligned}
\mathrm{S}_{2 \mathrm{~h}}= & 0.221171 t+0.182557 A+0.178385 B+0.000876 C \\
& -0.00118 D-0.00112 E+4.82514 \\
(\mathrm{CRC}= & \left.0.942855, R^{2}=0.887506, \text { Adj. } R^{2}=0.855448, n=27\right) \\
\mathrm{S} 2_{5 \mathrm{~h}}= & 0.154039 t+0.006524 A+0.210632 B+0.0015 C \\
& -0.00157 D-0.00082 E+10.87422 \\
(\mathrm{CRC}= & \left.0.971366, R^{2}=0.944552, \text { Adj } \cdot R^{2}=0.946346, n=54\right) .
\end{aligned}
$$

The SRA shows that the effect of $A, B$, and $C$ is positive while effect of $D$ and $E$ is negative.

$$
\begin{array}{r}
\mathrm{S} 2_{10 \mathrm{~h}}=0.114934 t+0.098263 A+0.429285 B-0.00038 C-0.00055 D-0.00226 E+8.20543 \\
\left(\mathrm{CRC}=0.969798, R^{2}=0.942314, \text { Adj. } R^{2}=0.936522, n=99\right) .
\end{array}
$$

By applying the LRA to DR, it was found that impact of $D$ is most critical while impact of $E$ is minimally noteworthy (see (8)) and then impact of $D$ and $B$ is most huge while impact of $A$ is irrelevant (see (9)). Also after $10 \mathrm{~h}$, impact of $A, C$, and $D$ was observed to be most critical while impact of $X_{2}{ }^{2}$ is most slightly noteworthy. The relapse examination was again led on DR after $10 \mathrm{~h}$ and it was found that impact of $X_{2}$ and $X_{1}{ }^{2}$ is most critical while impact of $C$ is insignificant (see (10)).

\subsubsection{3rd Batch}

$$
\begin{aligned}
\mathrm{S} 3= & 0.256874 t-0.26814 A-0.16514 B+0.000262 C \\
& +0.000548 D+0.006923 E+35.92275 \\
(\mathrm{CRC}= & \left.0.976225, R^{2}=0.957119, \text { Adj. } R^{2}=0.944255, n=27\right)
\end{aligned}
$$

$$
\begin{aligned}
\mathrm{S} 3= & 0.162851 t-0.31975 A-0.00574 B+0.00088 \mathrm{C} \\
& +0.00053 D+0.002823 E+44.42843 \\
(\mathrm{CRC}= & \left.0.976629, R^{2}=0.961753, \text { Adj. } R^{2}=0.954716, n=54\right) \\
\mathrm{S} 3_{10 \mathrm{~h}}= & 0.093693 t-0.24862 A+0.196631 B-0.00024 C \\
& +0.000654 D+0.000376 E+46.55 \\
(\mathrm{CRC}= & \left.0.951827, R^{2}=0.906334, \text { Adj. } R^{2}=0.901202, n=99\right)
\end{aligned}
$$

After drug release study, SRA shows that effect of $A$ and $B$ is more significant while effect of $C$ is negligible (see (11)). The effect of $A$ is most significant but effect of $E$ and $B$ is negligible (see (12)). For $10 \mathrm{~h}$ study, effect of $A$ and $D$ is significant while effect of $B$ and $C$ and $E$ is negligible (see (13)). 
TABLE 10: Standard regression analysis (SRA) and effects of variables on DR profiles.

\begin{tabular}{lcc}
\hline Batches & Time & Effects \\
\hline \multirow{2}{*}{ 1st } & $10 \mathrm{~h}$ & $B(0.96305)>D^{2}(0.60631)>C(0.511874)>E(0.467321)>A(0.15455)$ \\
& & $B(0.48382)>C(0.264335)>D(0.2517)>E(0.238427)>A(0.05542)$ \\
& & $B(0.95425)>D^{2}(0.60641)>C(0.510984)>E(0.468321)>A(0.15445)$ \\
2nd & $10 \mathrm{~h}$ & $D(0.78219)>A(0.437285)>C(0.319727)>B(0.257393)>E(0.19455)$ \\
& & $D(0.23438)>B(0.208289)>C(0.147678)>E(0.10895)>A(0.010716)$ \\
& & $B(0.322212)>D(0.24913)>E(0.20344)>A(0.122779)>C(0.07176)$ \\
3rd & $10 \mathrm{~h}$ & $A(0.68074)>D(0.476)>E(0.316554)>B(0.12522)>C(0.055576)$ \\
& & $A(0.51543)>D(0.320761)>C(0.112551)>E(0.084883)>B(0.00452)$ \\
4th & $B(0.36251)>D(0.280217)>B(0.085294)>C(0.03699)>E(0.017337)$ \\
& $10 \mathrm{~h}$ & $B(0.24738)>D(0.18553)>C(0.120534)>E(0.075439)>A(0.01652)$ \\
& $B(0.17275)>A(0.10162)>E(0.056415)>C(0.054636)>A(0.04857)$ \\
\hline
\end{tabular}

\subsubsection{4th Batch}

$$
\begin{array}{r}
\mathrm{S} 4=0.179377 t-0.06247 A-0.41753 B+0.001268 C-5.5 E-05 D+0.001364 E+24.487 \\
\left(\mathrm{CRC}=0.911831, R^{2}=0.818584, \text { Adj. } R^{2}=0.778545, n=27\right) \\
\mathrm{S} 4=0.145528 t-0.01115 A-0.46955 B+0.000945 C-0.00043 D+0.002388 E+27.266 \\
\left(\mathrm{CRC}=0.985076, R^{2}=0.952796, \text { Adj. } R^{2}=0.945592, n=99\right) \\
\mathrm{S}_{10 \mathrm{~h}}=0.121604 t-0.07896 A-0.45247 B+0.001672 C-0.00025 D+0.002678 E+37.27
\end{array}
$$$$
\left(\mathrm{CRC}=0.977618, R^{2}=0.954764, \text { Adj. } R^{2}=0.953648, n=99\right) .
$$

In drug release study for $2 \mathrm{~h}$, the effects of factors $B$ and $C$ are negligible but, in case of drug release study for $5 \mathrm{~h}$, the effects of the factors $B$ and $C$ become significant (see (14)). Similarly in drug release study for $5 \mathrm{~h}$, the effects of $B$ and $D$ become prominently significant, while, in studying the drug release for $10 \mathrm{~h}$, effects of $E$ and $A$ are negligible (see (15)). The effects of all variables are mentioned in Table 10.

\section{Conclusion}

The Psyllium husk is now an established herbal medicine for colon malignancy and heart ailments. The husk and its fractions are suitable as matrix for designing the floats due to having desirable pharmaceutical properties for designing controlled drug delivery system. The $3^{2}$ full factorial designs reveal that every independent variable of each formulation affects drug release rate of floats. The SRA (standard regression analysis) indicates that the level of parameters $A$ and $B$, in regression equations, plays vital role in procuring the coveted outcomes. The sign of variables in equation might be negative (decrease in the value of that variable) or positive (increase in the value of that variable) so their sums are adjustable to achieve the desired drug release profile. Excipients used in this work are mostly herbal in nature which are enlisted in GRAS (Generally Recognized as Safe) list and found to be biocompatible. The thermal study divulges that all polymer fractions are thermally stable and can withstand the environmental changes. The GPC (gel permeation chromatography) analysis indicates that polydispersity index (PDI) values of the different fractions have values between 2 and 3.75 but this difference has no significant effects on the drug release rate or disintegration of floats. Due to having tunable drug release profile and therapeutic significance, Psyllium husk and its fractions have potential utility in biomedical fields and food industries including designing of capsule shells and tablet matrix.
Abbreviations
$A=X 1:$ Independent factor 1
$B=X 2:$ Independent factor 2
GRAS: Generally Recognized as Safe
GRDDS: Gastroretentive drug delivery system
RNT: Ranitidine
DR: Drug release
PSG: $\quad$ Psyllium seed gel
LSG: $\quad$ Linseed gel 


$\begin{array}{ll}\text { TG: } & \text { Tragacanth } \\ \text { PSG: } & \text { Psyllium seed gel } \\ \text { CA: } & \text { Citric acid } \\ \text { SA: } & \text { Stearic acid } \\ \text { SnFm: } & \text { n represents the batch number and } m \\ & \text { represents the formulation number of that } \\ & \text { formulation } \\ \text { DDS: } & \text { Drug delivery system } \\ \text { LDS: } & \text { Low density system } \\ \text { GD: } & \text { Gastrointestinal } \\ \text { HG: } & \text { Husk gel } \\ f 1: & \text { Difference factors } \\ f 2: & \text { Similarity factor } \\ \text { H-Crowell: } & \text { Hixson Crowell } \\ \text { TA: } & \text { Thermal analysis } \\ \text { GPC: } & \text { Gel permeation chromatography } \\ \text { FT-IR: } & \text { Fourier transform-infrared spectroscopy } \\ \text { ENa: } & \text { Ethanol extract gel } \\ \text { MNa: } & \text { Methanol extracted gel } \\ \text { AANa: } & \text { Acetic acid extracted gel } \\ \text { ClfNa: } & \text { Chloroform extracted gel } \\ \text { ANa: } & \text { Acetone extracted } \\ \text { H: } & \text { Husk } \\ \text { SRA: } & \text { Standard regression analysis } \\ \text { LRA: } & \text { Linear regression analysis } \\ \text { SEM: } & \text { Scanning electron microscopy } \\ \text { WRV: } & \text { Water retention value } \\ \text { iPrOH: } & \text { Isopropyl alcohol } \\ \text { LT: } & \text { Lag time } \\ T_{g}: & \text { Glass transition temperature } \\ E_{a}: & \text { Activation energy } \\ \text { IPDT: } & \text { Integral procedural decomposition } \\ & \text { temperature } \\ \text { ITS: } & \text { Index of thermal stability } \\ \text { FWO: } & \text { Flynn-Wall-Ozawa } \\ \text { PDI: } & \text { Polydispersity index } \\ M_{n}: & \text { Number-average } \\ M_{w}: & \text { Weight-average } \\ M_{z}: & \text { Average molar masses } \\ \text { S4F3: } & \text { Standard tablet } \\ & \text { Fourth-batch third formulation. } \\ & \end{array}$

\section{Conflicts of Interest}

The authors declare that there are no conflicts of interest regarding the publishing of this paper.

\section{References}

[1] A. Chandel, K. Chauhan, B. Parashar, H. Kumar, and S. Arora, "Floating drug delivery systems: A better approach," International Current Pharmaceutical Journal, vol. 1, no. 5, 2012.

[2] P. Dongare, A. Darekar, S. Gondkar, and R. Saudagar, "Floating drug delivery system: A better approach," International Journal of Pharmacy and Biological Sciences, vol. 3, no. 4, pp. 72-85, 2013.

[3] S. Shah, J. Patel, and N. Patel, "Stomach specific floating drug delivery system: A review," International Journal of PharmTech Research, vol. 1, no. 3, pp. 623-633, 2009.
[4] P. Roy and A. Shahiwala, "Statistical optimization of ranitidine $\mathrm{HCl}$ floating pulsatile delivery system for chronotherapy of nocturnal acid breakthrough," European Journal of Pharmaceutical Sciences, vol. 37, no. 3-4, pp. 363-369, 2009.

[5] A. W. Basit and L. F. Lacey, "Colonic metabolism of ranitidine: Implications for its delivery and absorption," International Journal of Pharmaceutics, vol. 227, no. 1-2, pp. 157-165, 2001.

[6] C. L. Dikeman, M. R. Murphy, and G. C. Fahey Jr., "Dietary fibers affect viscosity of solutions and simulated human gastric and small intestinal digesta," Journal of Nutrition, vol. 136, no. 4, pp. 913-919, 2006.

[7] M. H. Fischer, N. Yu, G. R. Gray, J. Ralph, L. Anderson, and J. A. Marlett, "The gel-forming polysaccharide of psyllium husk (Plantago ovata Forsk)," Carbohydrate Research, vol. 339, no. 11, pp. 2009-2017, 2004.

[8] B. Bakde, "Fabrication of gastroretentive floating swellable matrices for oral controlled and sustained release of Famotidine," International Journal of Advances in Pharmaceutics, vol. 4, no. 4, pp. 34-39, 2015.

[9] G. J. Davies, P. W. Dettmar, and R. C. Hoare, "The influence of ispaghula husk on bowel habit," Journal of the Royal Society for the Promotion of Health, vol. 118, no. 5, pp. 267-271, 1998.

[10] C. Hallert, M. Kaldma, and B. G. Petersson, "Ispaghula husk may relieve gastrointestinal symptoms in ulcerative colitis in remission," Scandinavian Journal of Gastroenterology, vol. 26, no. 7, pp. 747-750, 1991.

[11] Y. Nakamura, J. E. Trosko, C.-C. Chang, and B. L. Upham, "Psyllium extracts decreased neoplastic phenotypes induced by the Ha-Ras oncogene transfected into a rat liver oval cell line," Cancer Letters, vol. 203, no. 1, pp. 13-24, 2004.

[12] J. R. Lightdale, D. A. Gremse, L. A. Heitlinger et al., "Gastroesophageal reflux: Management guidance for the pediatrician," Pediatrics, vol. 131, no. 5, pp. e1684-e1695, 2013.

[13] R. Kaza, E. Usharani, R. Nagaraju, R. Haribabu, and P. V. Siva Reddy, "Design and evaluation of sustained release floating tablets for the treatment of gastric ulcers," Journal of Pharmaceutical Sciences and Research, vol. 1, no. 4, pp. 81-87, 2009.

[14] K. Kavitha, N. Chary, G. Rajesh, S. Ramesh, and S. Shivaleela, "Formulation and evaluation of ranitidine floating tablets," International Journal of Pharmaceutical, Chemical \& Biological Sciences, vol. 3, no. 3, 2013.

[15] B. Abrahamsson, A. Pal, M. Sjöberg, M. Carlsson, E. Laurell, and J. G. Brasseur, "A novel in Vitro and numerical analysis of shear-induced drug release from extended-release tablets in the fed stomach," Pharmaceutical Research, vol. 22, no. 8, pp. 12151226, 2005

[16] S. Jamzad, L. Tutunji, and R. Fassihi, "Analysis of macromolecular changes and drug release from hydrophilic matrix systems," International Journal of Pharmaceutics, vol. 292, no. 1-2, pp. 75$85,2005$.

[17] J.-Y. Yin, S.-P. Nie, C. Zhou, Y. Wan, and M.-Y. Xie, "Chemical characteristics and antioxidant activities of polysaccharide purified from the seeds of Plantago asiatica L," Journal of the Science of Food and Agriculture, vol. 90, no. 2, pp. 210-217, 2010.

[18] A. Lazaridou and C. G. Biliaderis, "Thermophysical properties of chitosan, chitosan-starch and chitosan-pullulan films near the glass transition," Carbohydrate Polymers, vol. 48, no. 2, pp. 179-190, 2002.

[19] S. Saghir, M. S. Iqbal, A. Koschella, and T. Heinze, "Ethylation of arabinoxylan from Ispaghula (Plantago ovata) seed husk," Carbohydrate Polymers, vol. 77, no. 1, pp. 125-130, 2009. 
[20] A. X. Jin, J. L. Ren, F. Peng et al., "Comparative characterization of degraded and non-degradative hemicelluloses from barley straw and maize stems: Composition, structure, and thermal properties," Carbohydrate Polymers, vol. 78, no. 3, pp. 609-619, 2009.

[21] M. S. Iqbal, J. Akbar, S. Saghir et al., "Thermal studies of plant carbohydrate polymer hydrogels," Carbohydrate Polymers, vol. 86, no. 4, pp. 1775-1783, 2011.

[22] P. L. Ritger and N. A. Peppas, "A simple equation for description of solute release I. Fickian and Non- Fickian release from swellable devices," Journal of Controlled Release, vol. 5, no. 1, pp. 37-42, 1987. 

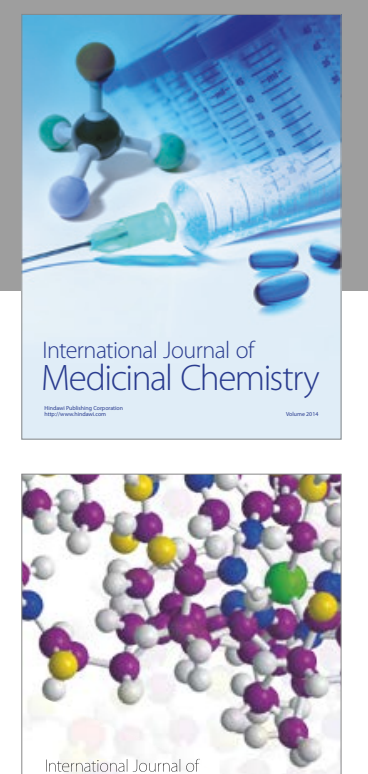

Carbohydrate Chemistry

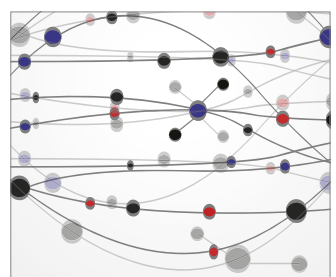

The Scientific World Journal
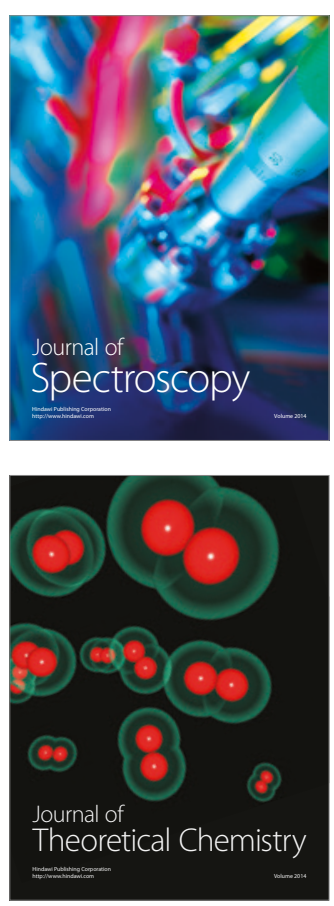
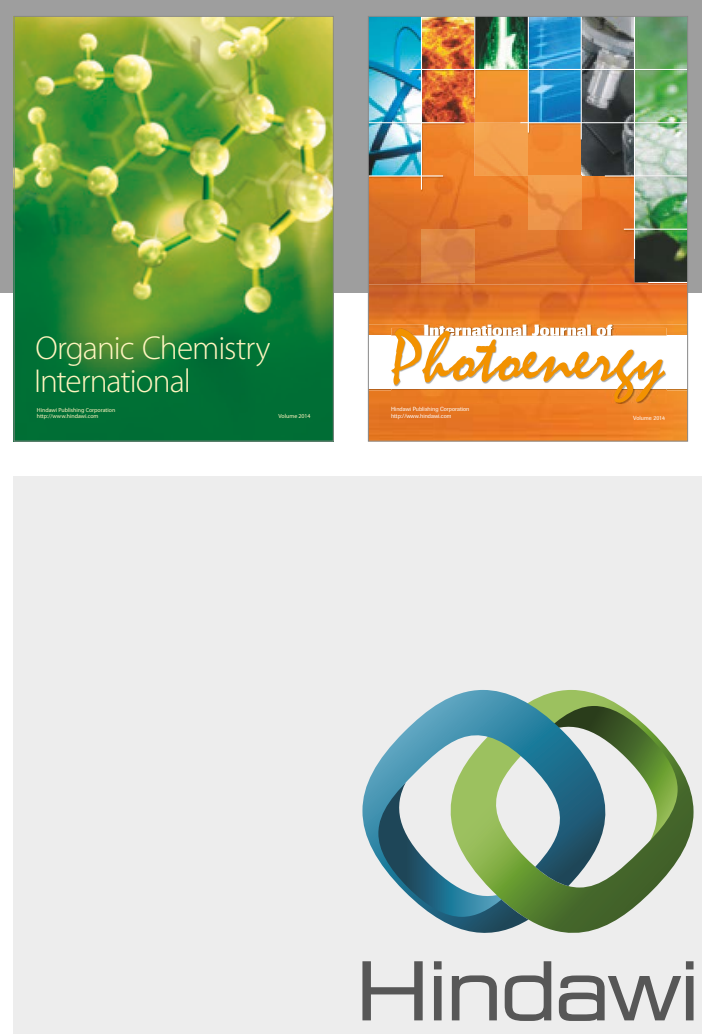

Submit your manuscripts at

https://www.hindawi.com

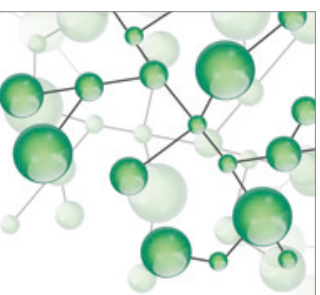

International Journal of

Inorganic Chemistry

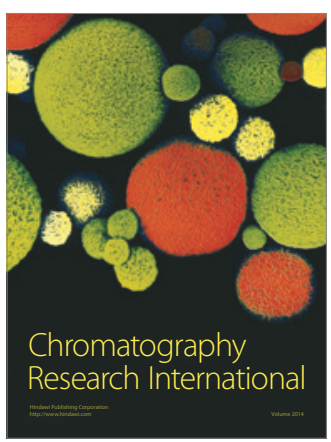

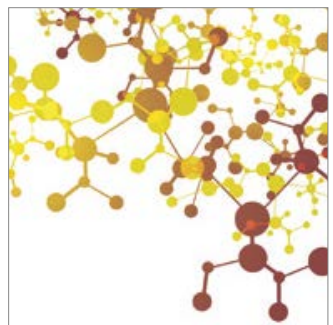

Applied Chemistry
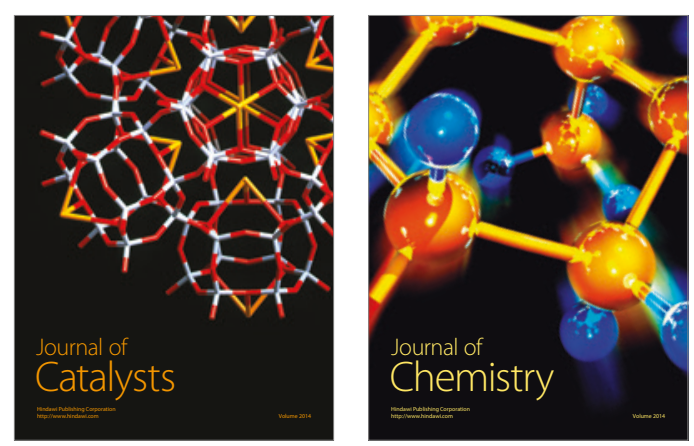
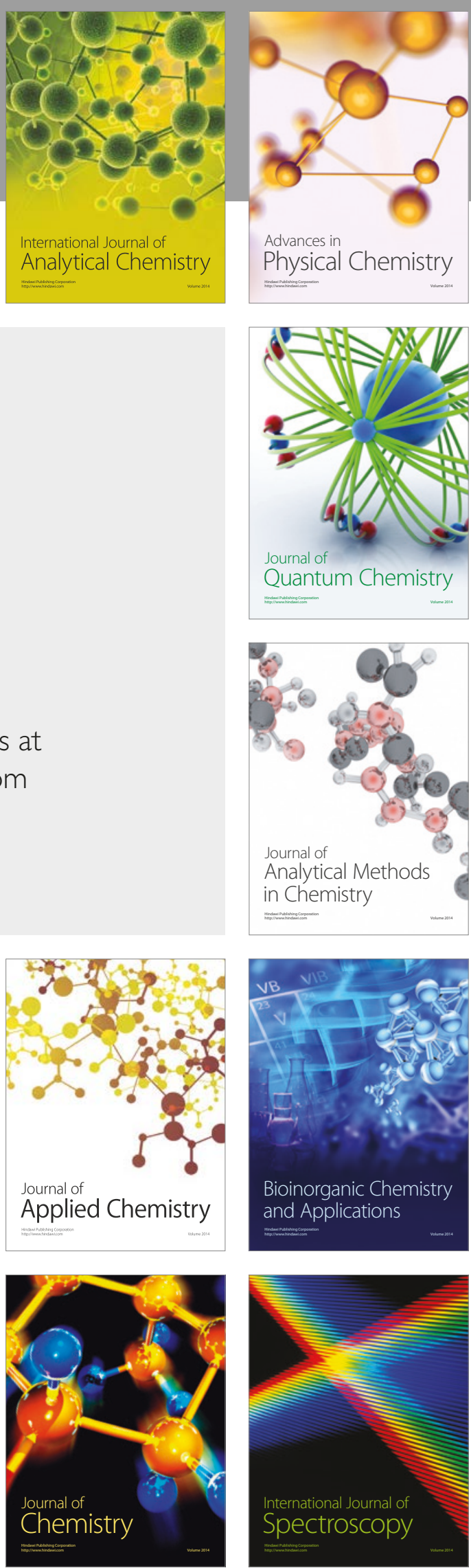